\title{
Free Thyroxine in Early Pregnancy and Risk of Developing Gestational Diabetes
}

Mohamed S. Fouad, Mohamed F. Ibrahim, Youssef M. Youssef*

Department of Obstetrics and Gynecology, Faculty of Medicine, Al-Azhar University

*Corresponding author: Youssef M, Youssef , E-Mail: dr.youssef.mohamed@gmail.com, Mobile: 002-01223291956

\begin{abstract}
Background: Pregnancy has a considerable physiological impact on the thyroid gland and its metabolic unction and to meet the increased demands during pregnancy. Thyroid disease is known to impact pregnancy outcomes, and gestational diabetes is the most common obstetric metabolic disease. Both of these conditions can cause short- and long-term harm to the mother and child, and an increasing number of scholars have therefore begun to investigate whether there is a correlation between thyroid disease and GDM

Objective: evaluation of the relations between different thyroid hormone levels in early pregnancy and the incidence of gestational diabetes mellitus (GDM).

Study design: This prospective observational cross-sectional study was conducted during the January 2018 to June 2018. The study comprised one hundred, euthyroid women with singleton pregnancy who provided early pregnancy serum samples for analyses of thyroid function. GDM was diagnosed using a 2 hours, 75 -g oral glucose tolerance test, and the mothers were grouped and compared according to the results.

Results: The incidence of GDM in pregnant women tended to increase with age $(P<.0001)$. The level of free $\mathrm{T}_{4}$ $\left(\mathrm{FT}_{4}\right)$ in early pregnancy in GDM women was lower than that in non GDM women $(P<.0001)$ also found that high maternal weight was associated with a higher GDM rate in the first trimester $(P<.0001)$.
\end{abstract}

Conclusion: Low thyroxine levels in early pregnancy could be a risk factor for GDM development.

Keywords: Gestational diabetes mellitus, free thyroxine, first trimester.

\section{INTRODUCTION}

Gestational diabetes mellitus (GDM) is one of the most common disorders complicating pregnancy, occurring in up to $14 \%$ of all pregnancies. The rise in GDM can likely be attributed to improved screening and diagnostic tools, as well as to the climbing rate of obesity. Excessive caloric intake and sedentary lifestyles are the major causative factors contributing to obesity ${ }^{(1)}$. The main pathophysiologic defects that occur in GDM are the same as those observed with T2DM: marked insulin resistance and impairment of insulin secretion. The exact mechanisms responsible for these defects in GDM are not known ${ }^{(2)}$.

All pregnancies are associated with an increase in insulin resistance and increased pancreatic insulin secretion as the pregnancy progresses. Skeletal muscle is the body's main site of glucose disposal and becomes insulin resistant during pregnancy. This insulin resistance begins in mid pregnancy and continues until the end of gestation. Pregnancies are also associated with a $200 \%$ to $250 \%$ increase in insulin secretion to maintain euglycemia in the mother. These metabolic changes are normal and provide adequate nourishment to the fetus. When maternal insulin secretion is unable to meet increased demand secondary to marked resistance, GDM results $^{(3)}$.

It is thought that the cumulative effects of maternal and placental influences result in abnormalities in insulin signaling pathways, which lead to decreased glucose uptake and an increase in insulin resistance. The exact molecular processes of such remain unclear ${ }^{(4)}$. Pregnancy has a considerable physiological impact on the thyroid gland and its metabolic function to meet the increased demands during pregnancy, the thyroid gland increases up to $40 \%$ in size, accompanied by an upsurge in the production of thyroid hormones, thyroxine (T4) and triiodothyronine (T3) $)^{(5)}$. Abnormalities in thyroid function are relatively prevalent among pregnant women, and have been linked to several obstetric complications including premature delivery and pregnancy loss, as well as adverse health outcomes in the offspring ${ }^{(5)}$.

Yet, the debate regarding the utility of routing screening and/or treatment of thyroid dysfunction during pregnancy is highly contentious, and remains to be resolved ${ }^{(5)}$. Given the important role thyroid hormones play in glucose metabolism and homeostasis, thyroid dysfunction has been suggested to play a role in the etiology of gestational diabetes mellitus (GDM), a common metabolic complication in pregnancy. However, the existing evidence has been conflicting and longitudinal data are sparse ${ }^{(6)}$.Of the two thyroid hormones T4 and T3, T4 is considered as prohormone, serving as a substrate for the biologically active form $\mathrm{T} 3$ where the conversion of peripheral $\mathrm{T} 4$ to $\mathrm{T} 3$, by two deiodinase enzymes, accounts for $80 \%$ of all the $\mathrm{T} 3$ produced; the rest is produced directly by the thyroid gland ${ }^{(7)}$.

In the present study, we investigated the associations of TSH and Free T4 levels as related markers of thyroid function while accounting for thyroid autoimmunity status. Since thyroid levels can change with the progression of pregnancy, we assessed these associations separately for the first trimester. 


\section{PATIENTS AND METHODS}

This prospective observational cross-sectional study was conducted at the Department of Obstetrics and Gynecology, Faculty of Medicine, Al Azhar University, (El-Hussin) hospital.

This study was approved by the Institutional Review Board of the Faculty of Medicine, Al Azhar University. From January 2018 to June 2018, 100 pregnant women who attended antenatal care visits at Al-Hussien University hospital outpatient clinic. The women provided early pregnancy serum samples for analyses of thyroid function.

\section{Inclusion criteria:}

1) A singleton pregnancy.

2) Completion of a 2 hours, 75 -g oral glucose tolerance test (OGTT) at 24-28 gestational weeks.

\section{Exclusion criteria:}

1) Diabetes before pregnancy or diabetes diagnosed during the first prenatal examination.

2) Polycystic ovary syndrome

3) Personal or family history of thyroid disease

4) Visible or palpable goiter

5) Taking hormone drugs that could affect thyroid function before or during pregnancy or receiving thyroid hormone replacement therapy

6) History of autoimmune disease

7) Multiple pregnancy.

\section{The candidates were subjected to:}

1. Full history taking.

2. Complete physical examination.

3. Complete obstetric examination including symphysis fundal length.

4. Complete ultrasound biometry.

5. Follow up till delivery, method of delivery and fetal outcome.

6. Thyroid function assessment: At the first antenatal visit (gestational age, 9-13 wk), maternal serum samples were collected in $10-\mathrm{mL}$ vacutainer tubes (free T4 normal range: $0.6-1.8 \mathrm{ng} / \mathrm{dl}$, TSH normal range: $0.4-4 \mathrm{mIU} / \mathrm{L}$ ).

All subjects provided written informed consent.

The least calculated number of female that could be included in that study was 86 patients.

Total of 100 participants were included, the calculation was based on a statistical significance level of $0.05 \%$ to yield a power of $90 \%$.

Gestational diabetes screening:

The women were screened for GDM at 24-28 weeks and classified at that time as having GDM in the index pregnancy if any abnormal plasma glucose values were obtained during the 2 hours, 75-g OGTT (1 step test).

Abnormal values were defined according to the following standard diagnostic criteria: a fasting level of $95 \mathrm{mg} / \mathrm{dL}(5.1 \mathrm{mmol} / \mathrm{L})$ or greater, a 1 -hour value of $180 \mathrm{mg} / \mathrm{dL}(10.0 \mathrm{mmol} / \mathrm{L})$ or greater, and a 2-hour value of $155 \mathrm{mg} / \mathrm{dL}(8.5 \mathrm{mmol} / \mathrm{L})$ or greater.

\section{RESULTS}

Clinical data of the candidates came as shown in Table (1).

Comparing candidates who developed GDM with those who didn't develop, incidence of GDM was significantly higher in candidates with lower free T4 levels $(\mathrm{P}<0.05)($ Table 2$)$.

Comparing both study groups regarding age, there was statistically significant increase in incidence of GDM with increase of maternal age ( $\mathrm{P}<$ 0.05) (Table 3).

Comparing the two studied groups according to BMI, statistically significant increase in the incidence of GDM with increase of maternal BMI $(\mathrm{P}<0.05)$ (Table 4).

While comparing TSH levels in both groups, no statistically significant difference was observed (Table 5).

Table (1): Clinical characteristics of the participants $(n=100)$

\begin{tabular}{||l|c|c|}
\hline Age & Number $(\mathbf{n}=\mathbf{1 0 0})$ & GDM (\%) \\
\hline $\mathbf{2 \mathbf { 2 3 }}$ & 26 & $1(7.1 \%)$ \\
$\mathbf{2 3 - 3 0}$ & 56 & $7(50 \%)$ \\
$\geq \mathbf{3 0}$ & 18 & $6(42.9 \%)$ \\
\hline $\mathbf{B M I}$ & & \\
\hline $\mathbf{1 8 . 5}$ & 12 & $2(16.6 \%)$ \\
$\mathbf{1 8 . 5 - 2 3 . 9}$ & 75 & $9(12 \%)$ \\
$\geq \mathbf{2 4}$ & 13 & $3(21.4 \%)$ \\
\hline Parity & & \\
Primigravida & 83 & $11(13.2 \%)$ \\
Multigravida & 17 & $3(17.6 \%)$ \\
\hline Family history of diabetes & & $7(11.1 \%)$ \\
\hline Without & 63 & $7(20.5 \%)$ \\
With & 34 & \\
\hline
\end{tabular}


Table (2): Comparison between the GDM group and Non- GDM groups according to free T4 levels in first trimester

\begin{tabular}{|c|c|c|c|c|c|c|c|c|}
\hline \multirow{3}{*}{ FT4 } & \multirow{2}{*}{\multicolumn{2}{|c|}{$\begin{array}{c}\text { Total } \\
(\mathbf{n}=\mathbf{1 0 0})\end{array}$}} & \multicolumn{4}{|c|}{ Thyroid hormone levels } & \multirow{3}{*}{$\begin{array}{c}\text { Test } \\
\text { of sig. }\end{array}$} & \multirow{3}{*}{ p } \\
\hline & & & \multicolumn{2}{|c|}{$\begin{array}{c}\text { Non-GDM } \\
(\mathrm{n}=86)\end{array}$} & \multicolumn{2}{|c|}{$\begin{array}{c}\text { GDM } \\
(n=14)\end{array}$} & & \\
\hline & No. & $\%$ & No. & $\%$ & No. & $\%$ & & \\
\hline $0.62-<1.2 \mathrm{ng} / \mathrm{dl}$ & 28 & 28.0 & 20 & 23.3 & 8 & 57.1 & $\overline{\square \square}$ & \\
\hline $1.2-<1.6 \mathrm{ng} / \mathrm{dl}$ & 22 & 22.0 & 18 & 20.9 & 4 & 28.06 & $\square \square \square$ & F* \\
\hline$\geq 1.6-1.8 \mathrm{ng} / \mathrm{dl}$ & 50 & 50.0 & 48 & 55.8 & 2 & 14.3 & $\square \square^{\square}$ & \\
\hline Min. - Max. & \multirow{3}{*}{\multicolumn{2}{|c|}{$\begin{array}{c}0.82-1.80 \\
1.41 \pm 0.34 \\
1.60\end{array}$}} & \multirow{3}{*}{\multicolumn{2}{|c|}{$\begin{array}{c}0.82-1.80 \\
1.46 \pm 0.33 \\
1.63\end{array}$}} & \multirow{3}{*}{\multicolumn{2}{|c|}{$\begin{array}{c}0.82-1.72 \\
1.13 \pm .32 \\
0.96\end{array}$}} & & \\
\hline Mean \pm SD & & & & & & & 3132 & $0.001^{*}$ \\
\hline Median & & & & & & & & \\
\hline
\end{tabular}

$\chi^{2}$ : Chi square test MC: Monte Carlo t: Student t-test $\quad \mathrm{p}$ : $\mathrm{p}$ value for comparing between the two groups

*: Statistically significant at $\mathrm{p} \leq 0.05$

Table (3): Comparison between the two studied groups according to maternal age

\begin{tabular}{|c|c|c|c|c|c|c|c|c|}
\hline \multirow{3}{*}{ Age (years) } & \multirow{2}{*}{\multicolumn{2}{|c|}{$\begin{array}{c}\text { Total } \\
(\mathbf{n}=\mathbf{1 0 0})\end{array}$}} & \multicolumn{4}{|c|}{ Thyroid hormone levels } & \multirow{3}{*}{$\begin{array}{c}\text { Test of } \\
\text { sig. }\end{array}$} & \multirow{3}{*}{$\mathbf{p}$} \\
\hline & & & \multicolumn{2}{|c|}{ Non-GDM $(n=86)$} & \multicolumn{2}{|c|}{ GDM $(n=14)$} & & \\
\hline & No. & $\%$ & No. & $\%$ & No. & $\%$ & & \\
\hline$<23$ & 26 & 26.0 & 25 & 29.1 & 1 & 7.1 & $\overline{\square^{\square}}$ & \\
\hline $23-29$ & 56 & 56.0 & 49 & 57.0 & 7 & 50.0 & ग००० & $\mathrm{p}=$ \\
\hline$\geq 30$ & 18 & 18.0 & 12 & 14.0 & 6 & 42.9 & $\square^{\square}$ & \\
\hline Min. - Max. & \multirow{3}{*}{\multicolumn{2}{|c|}{$\begin{array}{c}17.0-35.0 \\
25.57 \pm 4.56 \\
26.0\end{array}$}} & \multirow{3}{*}{\multicolumn{2}{|c|}{$\begin{array}{c}17.0-35.0 \\
25.06 \pm 4.41 \\
25.0\end{array}$}} & \multirow{3}{*}{\multicolumn{2}{|c|}{$\begin{array}{c}22.0-35.0 \\
28.71 \pm 4.34 \\
28.50\end{array}$}} & & \\
\hline Mean \pm SD & & & & & & & 2883 & $0.005^{*}$ \\
\hline Median & & & & & & & & \\
\hline
\end{tabular}

$\chi^{2}$ : Chi square test MC: Monte Carlo

t: Student t-test

$\mathrm{p}$ : $\mathrm{p}$ value for comparing between the two groups

*: Statistically significant at $\mathrm{p} \leq 0.05$

Table (4): Comparison between the two studied groups according to BMI $\left(\mathrm{kg} / \mathrm{m}^{2}\right)$

\begin{tabular}{|c|c|c|c|c|c|c|c|c|}
\hline \multirow[t]{2}{*}{ BMI $\left(\mathrm{kg} / \mathrm{m}^{2}\right)$} & \multicolumn{2}{|c|}{$\begin{array}{c}\text { Total } \\
(\mathbf{n}=100)\end{array}$} & \multicolumn{2}{|c|}{$\begin{array}{c}\text { Non-GDM } \\
(n=86)\end{array}$} & \multicolumn{2}{|c|}{$\begin{array}{c}\text { GDM } \\
(n=14)\end{array}$} & \multirow{2}{*}{$\begin{array}{l}\text { Test } \\
\text { of sig. }\end{array}$} & \multirow{2}{*}{$\mathbf{p}$} \\
\hline & No. & $\%$ & No. & $\%$ & No. & $\%$ & & \\
\hline$<18.5$ & 14 & 14.0 & 12 & 14.0 & 2 & 14.3 & $\square^{\square} \square$ & \\
\hline $18.5-23.9$ & 70 & 70.0 & 64 & 74.4 & 6 & 42.9 & $\square \square \square$ & $p=$ \\
\hline$\geq 24$ & 16 & 16.0 & 10 & 11.6 & 6 & 42.9 & $\square \square^{*}$ & \\
\hline Min. - Max. & \multirow{3}{*}{\multicolumn{2}{|c|}{$\begin{array}{c}16.20-27.30 \\
21.47 \pm 2.66 \\
21.40\end{array}$}} & \multirow{3}{*}{\multicolumn{2}{|c|}{$\begin{array}{c}16.20-27.30 \\
21.12 \pm 2.45 \\
20.95\end{array}$}} & \multirow{3}{*}{\multicolumn{2}{|c|}{$\begin{array}{c}18.0-27.0 \\
23.64 \pm 2.97 \\
23.55\end{array}$}} & & \\
\hline Mean \pm SD. & & & & & & & $3.455^{*}$ & $0.001^{*}$ \\
\hline Median & & & & & & & & \\
\hline
\end{tabular}

$\chi^{2}$ : Chi square test $\quad$ MC: Monte Carlo t: Student t-test $\quad \mathrm{p}: \mathrm{p}$ value for comparing between the two groups, *: Statistically significant at $\mathrm{p} \leq 0.05$

Table (5): Comparison between the two studied groups according to TSH

\begin{tabular}{|c|c|c|c|c|c|c|c|c|}
\hline \multirow{2}{*}{ TSH } & \multicolumn{2}{|c|}{ Total $(n=100)$} & \multicolumn{2}{|c|}{ Non-GDM $(n=86)$} & \multicolumn{2}{|c|}{$\operatorname{GDM}(n=14)$} & \multirow{2}{*}{ Test of sig. } & \multirow[b]{2}{*}{$\mathbf{p}$} \\
\hline & No. & $\%$ & No. & $\%$ & No. & $\%$ & & \\
\hline $0.4-<1$ & 24 & 24.0 & 21 & 24.4 & 3 & 21.4 & & \\
\hline $1-<2$ & 40 & 40.0 & 34 & 39.5 & 6 & 42.9 & $\square^{\square} \square$ & ${ }^{\mathrm{MC}} \mathrm{p}=$ \\
\hline $2-<3$ & 15 & 15.0 & 13 & 15.1 & 2 & 14.3 & $\square \square \square \square \square$ & 1.000 \\
\hline $3-4$ & 21 & 21.0 & 18 & 20.9 & 3 & 21.4 & & \\
\hline Min. - Max. & \multirow{2}{*}{\multicolumn{2}{|c|}{$\begin{array}{c}0.42-3.96 \\
1.90 \pm 1.05 \\
1.69\end{array}$}} & \multirow{2}{*}{\multicolumn{2}{|c|}{$\begin{array}{c}0.42-3.96 \\
1.90 \pm 1.06 \\
1.74\end{array}$}} & \multirow{2}{*}{\multicolumn{2}{|c|}{$\begin{array}{c}0.42-3.62 \\
1.92 \pm 1.06 \\
1.3\end{array}$}} & & \\
\hline $\begin{array}{l}\text { Mean } \pm \text { SD } \\
\text { Median }\end{array}$ & & & & & & & $\begin{array}{c}U= \\
590.0\end{array}$ & 0.905 \\
\hline
\end{tabular}

$\chi^{2}$ : Chi square test MC: Monte Carlo U: Mann Whitney test groups. *: Statistically significant at $\mathrm{p} \leq 0.05$ 


\section{DISCUSSION}

Thyroid disease and gestational diabetes are of the common obstetric metabolic disorders and known to impact pregnancy outcomes, both of these conditions can cause short- and long-term harm to the mother and child ${ }^{(9)}$.

Blood sugar levels and maternal thyroid function during pregnancy are influenced by various physiological hormones, such as estrogen, thyroidbinding globulin, human chorionic gonadotropin, placental lactogen, cortisol, and placental insulin enzyme (8). A pregnant woman's physiological characteristics are different from those in women who are not pregnant.

Although thyroid dysfunction in early pregnancy may have adverse effects on pregnancy outcomes, few studies have examined the relationship between maternal low free thyroxin (fT4) levels in first trimester of pregnancy and the incidence of $\operatorname{GDM}^{(\mathbf{1 0})}$.

Our study included 100 mothers who provided serum samples for analyses of thyroid function in first trimester. Gestational diabetes mellitus (GDM), was diagnosed using the oral glucose tolerance test and we concluded that the incidence of GDM was negatively correlated with maternal FT4 levels during early pregnancy.

This finding was reported by other studies ${ }^{(9,10)}$ who found increased risk of developing GDM when having low FT4 levels specifically in first trimester.

Haddow et al. ${ }^{(11)}$ in 2016 found a positive correlation between FT4 and GDM in second trimester but they didn't study the correlation in first trimester, while Oguz et al. ${ }^{(12)}$ in 2015 found a correlation between FT4 and GDM development in second and not first trimester.

On the other hand, Agarwal et al. ${ }^{(13)} 2006$ found no correlation between thyroid dysfunction and GDM risk.

Studies of general populations have shown that several mechanisms are involved in the thyroid hormone-mediated regulation of glucose metabolism (11). Specifically, thyroid hormones can:

1) Reduce the half-life of insulin, accelerate the rate at which insulin is degraded, and increase the release of the inactive precursors of insulin ${ }^{(11)}$.

2) Promote hepatic glucose output by increasing the expression of glucose transporter 2 in liver cell membranes ${ }^{(14)}$.

3) Activate $\beta$-adrenergic receptors via cyclina AMP (cAMP), which increases the sensitivity of catecholamines, powerful hormones that accelerate glycogenolysis ${ }^{(\mathbf{1 4})}$.

Studies have also shown that many of the pathways between the hypothalamic-pituitary axis and the T3 receptor in thyroid cells are abnormal in patients with diabetes ${ }^{(14)}$.

Therefore, a variety of separate associations have been identified between thyroid function and glucose metabolism, and these provide common pathways through which thyroid dysfunction and diabetes can develop ${ }^{(15)}$.

In accordance with the findings in our study, it has previously been shown that patients with either hypothyroidism or subclinical hypothyroidism can exhibit insulin resistance ${ }^{(15)}$.

Another possible explanation that might explain the relation between low freeT4 levels and GDM was proposed by Haddow et al. ${ }^{(11)} 2016$ who studied the relation between thyroid hormone levels and BMI. They linked obesity with induction of triiodothyronine (T3) which is the hormonal product responsible for stimulating endogenous glucose production.

Obesity induces increased deiodinase activity, as indicated by a combination of higher T3 and lower T4 levels ${ }^{(16)}$.

In their study, free T4 levels were used as the marker for deiodinase activity and concluded that ectopic accumulation of fat in liver and muscle associated with over-nutrition is the best understood causal agent for insulin resistance and type 2 diabetes (via diacylglycerol-induced inhibition of insulin receptor substrate) connecting higher weight on the one hand with deiodinase activity and gestational diabetes on the other.

There are several advantages to our study. First, we excluded patients with a variety of thyroiditis and immune system diseases, and patients with diabetes caused by immune disorders were also excluded because of previous reports showing that autoimmune thyroiditis is closely associated with type 1 diabetes. Second, our study excluded patients who were taking hormonal therapy or and other drugs, either before or during pregnancy, that could affect thyroid function in addition to patients who were receiving thyroid hormone replacement therapy.

This allowed us to explore correlations between thyroid hormone levels in early pregnancy and GDM in a natural setting.

Our study showed also that older maternal age and higher BMI could be risk factor for developing GDM in pregnancy which was consistent with other studies $^{(17,18)}$.

Another conclusion our study brought that TSH levels can't be correlated with risk of GDM development which lies in accordance with other studies $^{(11)}$.

Our study results show that low FT4 levels in early pregnancy are associated with GDM. Therefore, 
early measurement of FT4 levels could predict the possibility of GDM occurrence in this pregnancy.

Conclusion: Low free thyroxine levels in early pregnancy could be a risk factor for GDM development.

\section{REFERENCES}

1. Dabelea D, Snell-Bergeon JK, Hartsfield CL, Bischoff KJ, Hamman RF, McDuffie RS (2005): Increasing prevalence of gestational diabetes mellitus (GDM) over time and by birth cohort: Kaiser Permanente of Colorado GDM Screening Program. Diabetes Care, 28(3):579-84.

2. Buchanan TA, Xiang A, Kjos SL, Watanabe R (2007): What is gestational diabetes? Diabetes Care, 30 (2):S10511.

3. Desoye G, Hauguel-de Mouzon S (2007): The human placenta in gestational diabetesmellitus. The insulin and cytokine network. Diabetes Care, 30:S120-6.

4. Perkins JM, Dunn JP and Jagasia SM (2011): Perspectives in gestational diabetes mellitus: a review of screening, diagnosis, and treatment. Clin Diabetes, 25(2):57-62

5. Alexander EK, Pearce EN, Brent GA, Brown RS, Chen H, Dosiou C et al.(2017): Guidelines of the American Thyroid Association for the Diagnosis and Management of Thyroid Disease During Pregnancy and the Postpartum. Thyroid, 27:315-38.

6. Toulis KA, Stagnaro-Green A, Negro R (2014): Maternal subclinical hypothyroidsm and gestational diabetes mellitus: a meta-analysis. Endocr Pract 20:70314.

7. Maia AL, Goemann IM, Meyer EL, Wajner SM (2011): Deiodinases: the balance of thyroid hormone: type 1 iodothyronine deiodinase in human physiology and disease. J Endocrinol., 209:283-97.

8. Lazarus JH(2011): Thyroid function in pregnancy. $\mathrm{Br}$ Med Bull ., 97:137-48.

9. Olivieri A, Valensise H, Magnani F, Medda E, De Angelis S, D'Archivio M et al. (2000): High frequency of antithyroid autoantibodies in pregnant women at increased risk of gestational diabetes mellitus. Eur J Endocrinol., 143(6): 741-7.

10.Zhang Y, Dai X, Yang S, Zhang C, Han M, Huang HF et al. (2017): Maternal low thyroxin levels are associated with adverse pregnancy outcomes in a Chinese population. PLoS One, 12(5):e0178100.

11. Haddow JE, Craig WY, Neveux LM, Palomaki GE, Lambert-Messerlian G, Malone FD et al. (2016): Free Thyroxine During Early Pregnancy and Risk for Gestational Diabetes. PLoS ONE, 11(2): e0149065.

12. Oguz A, Tuzun D, Sahin M, Usluogullari AC, Usluogullari B, Celik A et al. (2015): Frequency of isolated maternal hypothyroxinemia in women with gestational diabetes mellitus in a moderately iodinedeficient area. Gynecol Endocrinol., 31(10): 1-4.

13. Agarwal MM, Dhatt GS, Punnose J, Bishawi B, Zayed R (2006): Thyroid function abnormalities and antithyroid antibody prevalence in pregnant women at high risk for gestational diabetes mellitus. Gynecol Endocrinol., 22(5):261-6.

14. Kemp HF, Hundal HS, Taylor PM (1997): Glucose transport correlates with GLUT2 abundance in rat liver during altered thyroid status. Mol Cell Endocrinol., 128:97-102.

15. Maratou E, Hadjidakis DJ, Kollias A (2009): Studies of insulin resistance in patients with clinical and subclinical hypothyroidism. Eur J Endocrinol., 160:785-90.

16. Haddow JE, Neveux LM, Palomaki GE, LambertMesserlian G, Malone FD, D'Alton ME (2015): An inverse relationship between weight and free thyroxine during early gestation among women treated for hypothyroidism. Thyroid, 25(8):949-53.

17.Solomon CG, Willett WC, Carey VJ (1997): A Prospective Study of Pregravid Determinants of Gestational Diabetes Mellitus. JAMA., 278(13):1078-83.

18. Khalil A, Syngelaki A, Maiz N, Zinevich Y, Nicolaides KH (2013): Maternal age and adverse pregnancy outcome: a cohort study. Ultrasound Obstet Gynecol., 42(6):634-43. 